\title{
MEASUREMENTS AND SIMILLATION OF CONTROLLED BEAMFRONT MOTION IN THE LASER CONTROLLED COLLECTIVE ACCELERATOR*
}

\author{
R.L. Yao, W.W. Destler. C.D. Striffler, J. Rodgers, Z. Scgalor \\ University of Maryland. College Park, MD 207+2 \\ ACO 5-85ER He2/6:
}

\section{Abstract}

In the Laser Controlled Collective Accelerator, an intense electron beam is injected at a cursent above the vacuum space charge limit into an initially evacuated drift tube. A piams channed, produced by time-sequenced. multiple laser beam ionization of a solid target on the drift tube wall, provides the neeeasary neutralization so allow for effective beam propagation. By controlling the rate of production of the plasma channel as a function of time down the drift tube, control of the electroo beamiront can be achieved. Recent experimental measure- i ments of controlled beamiront motion in this configuration are presented, soas with rexults of ion acceleration experiments conducted uing two different accelerating gradients. These rexulte are compared with numerical simulations of the sytem in which both controlied besmiront motion and ion acceleretion is obeerved consiatent with both design expectations and experimeatal resulta.

\section{Introduction}

The Laser Controlled Collcetive Accelerator concept ${ }^{3-3}$ represents an attempt to extend the promising results from "naturaily occursing" collective ion acceleration experiments to practical accelerators in which the accelerating gradient and distance can be systematically controlled. The concept is similar to that employed in the IFA-1 and IFA-2 experiments. of Olson", although the actual experimental configuration is quite difierent. The busic concept bethind the experiment is shown in Fig. 1. An intense relativistic electron benm is injected through a bealized gas cloud into an eracuated drift tube at a current well above the vacuum space charge limit. A virtual cathode then forms immedistely downtrean of the injection point and iom produced within the localized gas cloud. are eccelerated to modeat energies in a manner similar to more: conventional collective accelerators. At this point, a channel| of plasm is produced in a time sequenced manner down the drift tube by lece ionization of a $\mathrm{CH}_{2}$ target strip located on the drift tube mull. The time sequencing of the plasms channet is achieved by dividing a Q-switched ruby laser pulse into ten approximatcly equal energy beams and using optical delays to ionize sequentially ten target spots equally spaced down the drift tube. In this manner, the virtual eathode at the beam-! front can be carefully sccelerated down the drift tube and ions. trapped by the atrong clectric ficlds at the virtual cathode can be accelerated to high energies in a controiled manner.

In this paper we present in section II rcsults of experiments in which controlled beamfront motion has been confirmed for two different accelerating gradients. Results of ion acceleration experiments are aleo picsented. Numeticnl simulations of the experiments presented in seetion III contirm both controlted beamiroat motion and the controlled acecleration of ions by the moving virtual cachode over significant distances. Couclusiona are drawn in section IV.

\section{Experiments}

As shown in Fig. 1, an intense relativistic electron beam ( $900 \mathrm{keV}, 20 \mathrm{kA}, 30 \mathrm{~ns}$ ) is emitced from a $4 \mathrm{~mm}$ diameter tuossten cathode beated $1 \mathrm{~cm}$ upstream of a strialeas sted anode. A $14 \mathrm{~mm}$ diancter hole in the anode plate an axis allows amost all of the beam current to pass into a downstream drift tube $10 \mathrm{~cm}$ in diameter. Seed proton for aceelention are provided by beam ionization of a localized gas eloud produced by a fat gas puff valve. The Q-switched ruby laner pulse (6 J, 15 ns) is divided into ten approximucely equal enosos benos and optically delayed to provide a time-sequenced source of ions down the $50 \mathrm{em}$ lengtb of the drift tube Design considerations for the expesiment and resuits of tests of the optical system have been reported previously. ${ }^{2,3}$

Five current collecting wall probes were installed to mensure beam current deflected to the drift tube wall at the beamfront as a function of time. These probes were bocated at axini positions 10, 20,30, 40 , and $50 \mathrm{~cm}$ downatrenm of the anode plase. Total current reaching the downstrenen ead of the drift tube was mearured using a Faraday cup, and accelernted ion energiea mere meanured using stacked foil activeion techniques. Titanium ( $\left.\mathrm{Ti}^{47}(\mathrm{p}, \mathrm{n}) \mathrm{V}^{47}\right)$ and Copper $\left(\mathrm{Cu}^{\mathrm{N}}(\mathrm{p}, \mathrm{n}) \mathrm{Zn}^{40}\right)$ reactions were used having threshold energies of 3.7 and $4.2 \mathrm{MeV}$, respectively. A silver activition neutron counter tecorded neutrons produced by these reactions and by necelerated protons striking the drift tube walls.

Experimental dats has been obthined for two difierent ac. celerating gradientr; one at $40 \mathrm{MIcV} / \mathrm{m}$ over a $50 \mathrm{~cm}$ acceleratiog distance and one at $90 \mathrm{MeV} / \mathrm{m}$ over the same distance. Date from the five wall current probes for the smaller gradien are sbom in Fig. 2 for a) the case when the her in fircd $200 \mathrm{~m}$ in edrunce of the beam, b) the case whete the luser is not fired at all, and c) the case where the laser timing inch that the plawn is produced by laser-target interactions at the same time a the beam is being injected (optimal timing). As can be readily seen from these results, good control ower the beamiront motion has been achieved when the lace-beam tim. ing is optimal. Meanurements of the acceleraced ion energy and propagased current, shown in Fig. J, clcarly show that procons can be sceeleraled up to the designed output energy when the lner -bean timing is such as to allow control of the beamfront.

Experimental data obtained at the hipher secelerating gradient of $90 \mathrm{MV} / \mathrm{m}$ sloo indieate good control oret the beam. front motion, but peak ion energies observed are ectunlly lese than those obeerved for the lower gendient experiments. This is uidoubtedly due to a reduction in the chetric ficld strength at the virtual cathode below $\mathbf{0 0} \mathrm{MIV} /$ in at some point in the aceeleration process. The following results of unmerical simulations of the experiments shed ndelitional light ont this scesult.

\section{Numerienl simulations.}

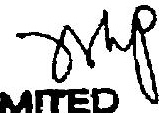

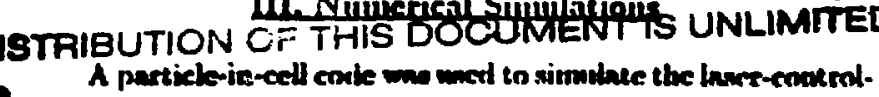

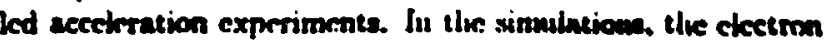

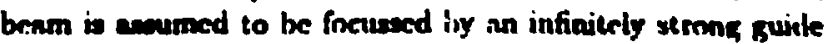
magnetic feld so that the partirles mave mily abong the nxis of 
the drift tuoe. The radius of the beam is aiso assumed to be :nucin icss than the radius of the driti tube so that the charge lensity. current densicy. and axial electrical field are approxinateiy constant across the bearn cross-section. Ionization of the neutral gas is modelled by keeping traci of the amount of onization produced by coilisions with electrons and ions and introducıng eiectrons and ions apnropriately.

In the simulations. che laser-nrociuced piasma is assumed to completely neurralize the space-charge on the axis of the irift tube once it reaches the electron beam from the wail. The time required for the laser-produced plasma to reach the electron beam from the wail is assumed to be given by the time required for a proton to fall through a logarithmic potential drop $V_{0}$ from $r=R_{*}$ to $r=R_{3}$. where $V_{j}$ is the electson beam voltage. $R_{z}$ is the wall radius and $R$, is the beam radius.

Results are shown for a $000-\mathrm{kV}, 20-\mathrm{kA}, 1-\mathrm{cm}$-radius electron beam which is injected into a 5 -cm-radius. $50-\mathrm{cm}-\mathrm{lons}$ drift tube with a 2-cm-wide. 100-m Torr hydrogen gas cioud bcated next to the anode plane. Ihe front of the laser beam is assumed to travel sown the drift tube at a velocity which increases linearly froun $\delta_{i}=0.04$ to $d_{f}=0.2$ over a distance of 45 em. corresponding to sn accelerating gradient of $40 \mathrm{MeV} / \mathrm{m}$.

Figure 4 show the peak proton energy measured at $45 \mathrm{~cm}$ versus the time delay between the start of the laser pulse and the start of the beam pulse $\tau_{L}-\tau_{B}$. In plotting this data, we assumed that the laser requires $10 \mathrm{~ns}$ to produce plasma aiter striking the target on the wall. For a wide range of $\tau_{L}-\tau_{B}$, the peak proton energy which was measured actually exceeds the design value of $18.76 \mathrm{MleV}$.

Figure 5 shows the velocity versus position for an accelerated proton for $\tau_{L}-\tau_{B}=-8 \mathrm{~ns}$. Also shown in the figure is the velocity versus position for the front of the laser besm. The proton is acceierated relatively smoothly from an initial velocity of $0.04 \mathrm{c}$ to a final velocicy of $0.2 \mathrm{c}$.

In all runs the peak electric field $E_{z}$ fell by an order of masnitude, e.g. from $3 \times 10^{\circ} \mathrm{V} / \mathrm{m}$ to $5 \times 10^{i} \mathrm{~V} / \mathrm{m}$. as the beam front moved downstream. Figure 6 shows the magnitude versus bcation of the peak $E_{z}$ at a number of time step approximutely 2 ns apart for one run. The decrense in the strength of the peak electric field observed in the simuiations is consistent with the experimental observation that the peni ion energy actually fell when a ligher accelerating gradient was used.

\section{Conclusions}

In conclusion. both experiments and numerical simulation now indicate that the laser-concrolled collective accelerator concept is a promising one. Effective control over the propagation of a virtual cathode at the front of an iutrnse relativistic electron beam has been achieved. and protons liave been accelerated at a rate of $10 \mathrm{MV} / \mathrm{m}$ orrs a ristance of about $50 \mathrm{~cm}$. Furthermore. numerical simulations indicate that significantly higher ion energies can be achieved by pither using longer accelerating, distances / and consequent|y: Ionger injected electron beam pulse durations/ and/or by injectine hizher energy electron hearns to maintain higher electric ticid strengths at the virtual cathode.

\section{References}

1. P.G. OShea. H. IV. Distier. I. Rurlgers, aud Z. Segalov. Appl. Plits. Lett. 12.1030 (1050).

2. W.IV. Destier. P.G. O'Slirn. I. Rinters. and Z. Sezabov.

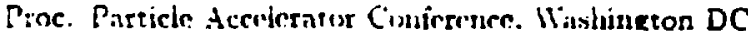

.Iarch 16-10. 1057. p. i03.

3. IV.W. Dcstler. J. Roderers. and Z. Sexaios. submitted to J. Appl. Phys.. Fè. 1989.

4. C.L. Olson and U. Schumaciner. in Soringer Tracts in Modern Physics: Collectuve lon ticeieration. eaited by G. Hobler ISpringer. New York. iJ701. Vol. 34 .

5. C.L. Olson, C.A. Front. E.L. Patterson. J.P. Antbes. and J.IV. Poukey. Phys. Rev. Lect. ㅎ6, 2260 (1956).

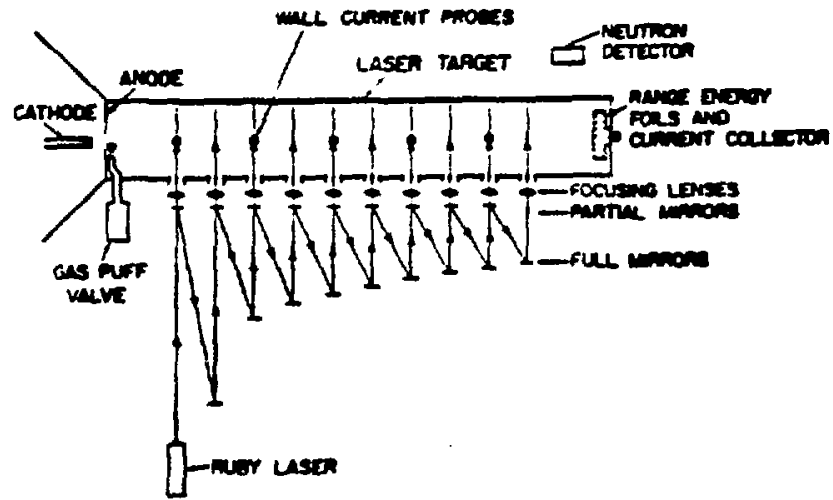

Fig. 1. Experimental Configuration.

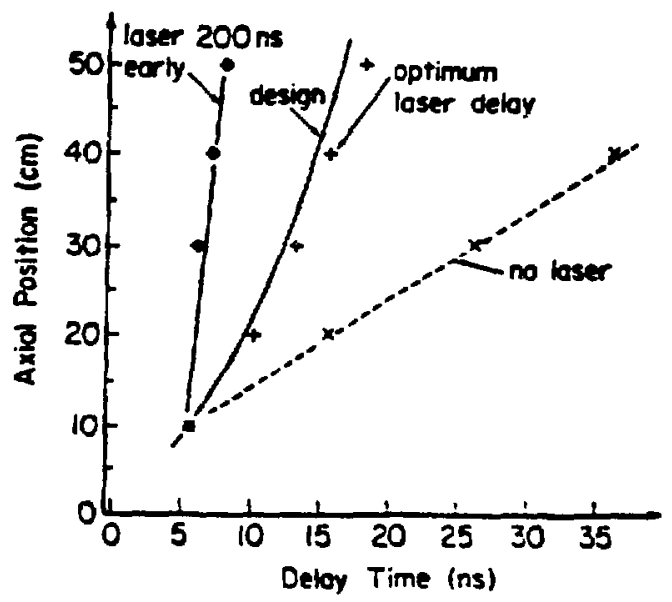

Fic. 2. Data from 5 axiaily spaced current collectors located on drift tube wadl 

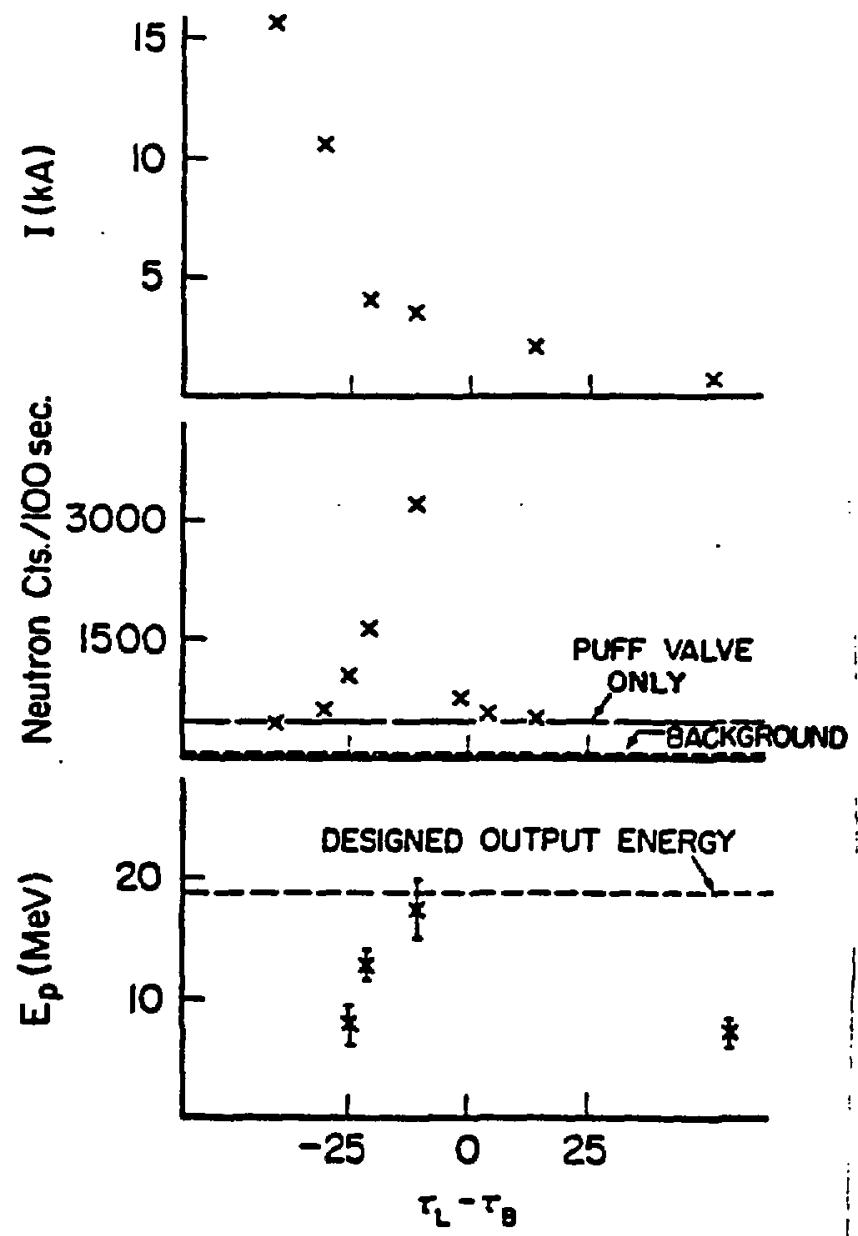

Fig. 3. Propagated current at $50 \mathrm{em}$, deutron counte. and penk proton cnergy v. beam-laver firing delay.

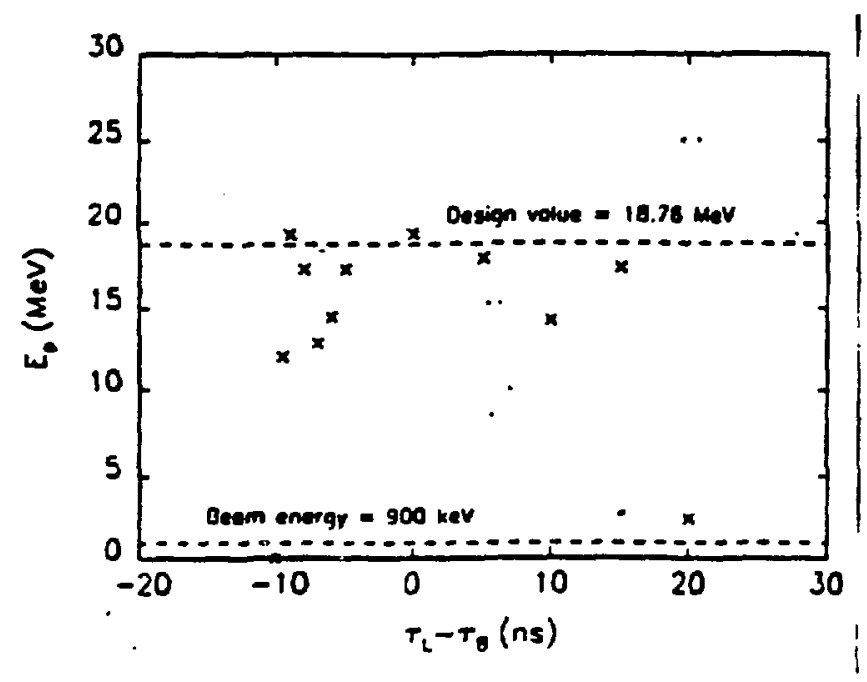

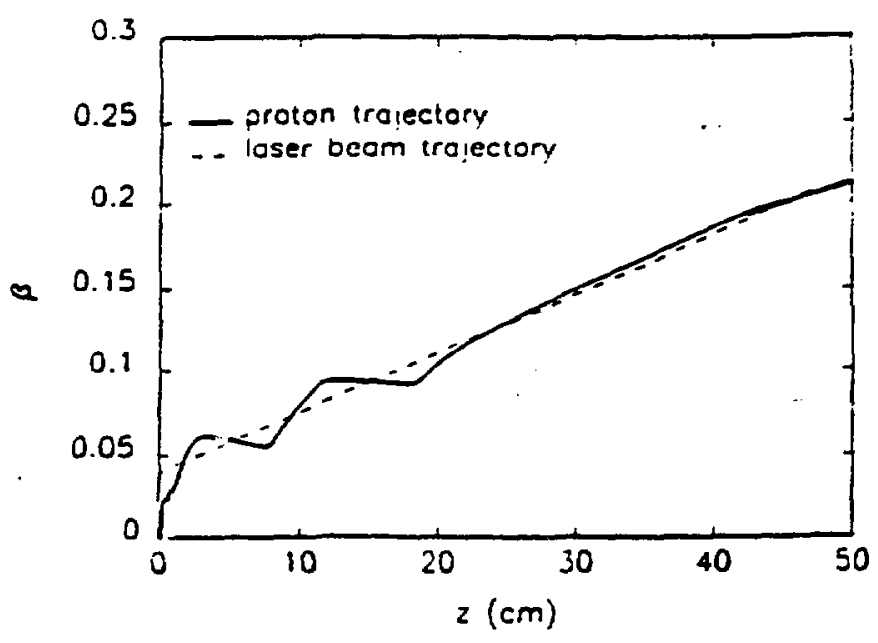

Fig. 5. Velocity vs. position for acceleraced proton.

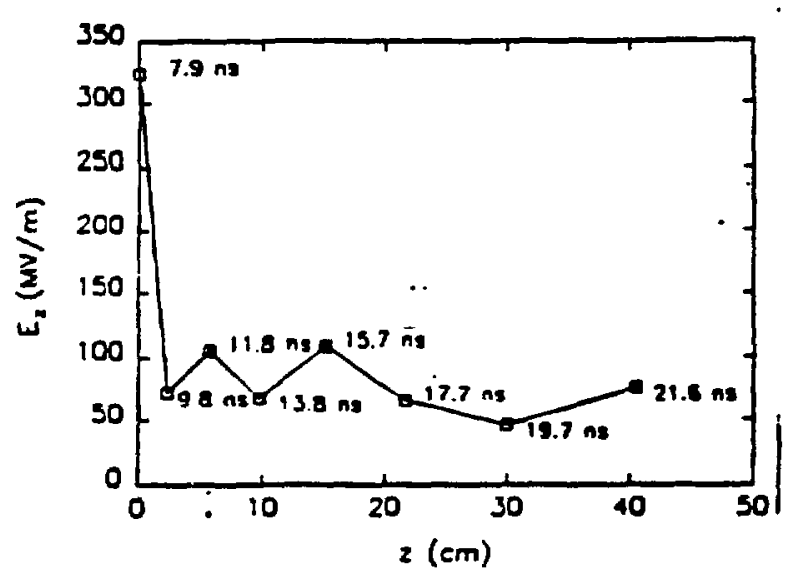

Fig. 6. Magnitude vg. location of peak clectric ficid.

Fif. 4. Peak proton enerey mennured of $45 \mathrm{~cm}$ vs. time delay. 


\section{DISCLAIMER}

This report was prepared as an account of work sponsored by an agency of the United States Government. Neither the United States Government nor any agency thereof, nor any of their employees, makes any warranty, express or implied, or assumes any legal liability or responsibility for the accuracy, completeness, or usefulness of any information, apparatus, product, or process disclosed, or represents that its use would not infringe privately owned rights. Reference herein to any specific commercial product, process, or service by trade name, trademark, manufacturer, or otherwise does not necessarily constitute or imply its endorsement, recommendation, or favoring by the United States Government or any agency thereof. The views and opinions of authors expressed herein do not necessarily state or reflect those of the United States Government or any agency thereof. 